\title{
Review for Fixed Point Theory and Applications 2012, 2012:74 (By Madjid Eshaghi Gordji et.al )"
}

\author{
Shunli Jin \\ Department of Mathematics \\ Cangzhou Normal University, \\ Cangzhou,China \\ e-mail: hbczsfjsl@sina.com
}

\author{
Yongfu Su \\ .Department of Mathematics \\ Tianjin Polytechnic University \\ Tianjin, China \\ e-mail::tjsuyongfu@163.com
}

\begin{abstract}
In this paper we point out the following two points. Firstly, the result of Madjid Eshaghi Gordji et.al [ Madjid Eshaghi Gordji, Maryam Ramezani1, Yeol Je Cho and Saeideh Pirbavafa, A generalization of Geraghty's theorem in partially ordered metric spaces and applications to ordinary differential equations, Fixed Point Theory and Applications 2012, 2012:74] can be easily obtained from the result of [ Amini-Harandi. A, Emami, H: A fixed point theorem for contraction type maps in partially ordered differential equations. Nonlinear Anal. 72, 2238-2242 (2010)], so that the longer proof of the result is not necessary. Secondly, the existence of solution for a initial-value problem does not needed the application of the result of Madjid Eshaghi Gordji et.al, we can also apply the result of AminiHarandi. A et.al to get the the existence of solution for this initial-value problem and to get more generalized results.

Keywords-Contraction mapping principle; Partially ordered metric spaces; Fixed point; The initial-value problem;Application.
\end{abstract}

\section{INTRODUCTION}

Fixed point theory plays a basic role in applications of many branches of mathematics. It becomes the center of strong research activity that find a fixed point of contractive mappings. Banach contraction mapping principle is a classical and powerful tool in nonlinear analysis. Weak contractions are generalizations of Banach contraction mapping, which have been studied by several authors. In [1-8], the authors prove some types of weak contractions in complete metric spaces respectively. In particular, existence of fixed point for weak contraction and generalized contractions was extended to partially ordered metric spaces in [2,9-24]. Among them, some involve altering distance functions. Such functions were introduced by Khan et al.in [1], where they present some fixed point theorems with the help of such functions.

On the other hand, Geraghty's contractive mappings was firstly introduced by Geraghty in 1973. Since then, several papers have dealt with fixed point theory on Geraghty's contractive mappings. In addition, many authors have extended, generalized and improved the fixed point of this kind of contractive mappings in not only metric spaces but also partially ordered metric space.
It is our purpose in this paper first to give an easy proof of the result of Madjid Eshaghi Gordji et.al. Then we extend the result of Amini-Harandi . A et.al, o get the the existence of solution for this initial-value problem and to get more generalized results.

\section{THE RESUlT OF MADJID ESHAGHI GORDJI ET.AL}

In this section, we first recall some important and useful definitions and lemmas. The following class of functions is used in [1].

Let $\mathfrak{R}$ denote the class of those function $\beta:[0, \infty) \rightarrow[0,1)$ which satisfies the condition:

$$
\beta\left(t_{n}\right) \rightarrow 1 \Rightarrow t_{n} \rightarrow 0 .
$$

In 1973, Geraghty introduced Geraghty contraction and obtained the fixed point theorem. Definition.([28]) Let $(X, d)$ be a metric space. A mapping $T: X \rightarrow X$ is said to be a Geraghty contraction if there exists $\beta \in \mathfrak{R}$ such that for any $x, y \in X$

$$
d(T x, T y) \leq \beta(d(x, y)) \cdot d(x, y) .
$$

Theorem. ([28]) Let $(X, d)$ be a complete metric space and $T: X \rightarrow X$ be a Geraghty-contraction. Then $T$ has a unique fixed point $x^{*}$ and for any $x_{0} \in X$, the iterative sequence $x_{n+1}=T x_{n}$ converges to $x^{*}$.

Very recently, A. Amini-Harandi and H. Emami proved a fixed point theorem for contraction type maps in partially ordered metric spaces in [25]. 
Theorem 1. [1] Let $(X, \leq)$ be a partially ordered set and suppose that there exists a metric $d$ in $X$ such that $(X, d)$ is a complete metric space. Let $f: X \rightarrow X$ be an increasing mapping such that there exists an element $x_{0} \in X$ with $x_{0} \leq f\left(x_{0}\right)$. Suppose that there exists $\beta \in \mathfrak{R}$ such that

$$
d(f(x), f(y)) \leq \beta(d(x, y)) d(x, y),
$$

for each $x, y \in X$ with $x \geq y$.

Assume that either $f$ is continuous or $X$ is such that if an increasing sequence $x_{n} \rightarrow x \in X$, then $x_{n} \leq x$, $\forall n$.Then $f$ has a fixed point. Besides, if for each $x, y \in X$, there exists $z \in X$ which is comparable to $x$ and $y$. Then ${ }^{f}$ has a unique fixed point.

Let $\Psi$ denotes the class of the functions $\psi:[0,+\infty) \rightarrow[0,+\infty)$ which satisfies the following conditions:

(1) $\psi$ is nondecreasing;

(2) $\psi$ is sub-additive, that is, $\psi(t+s) \leq \psi(t)+\psi(t)$;

(3) $\psi$ is continuous;

(4) $\psi(t)=0 \Leftrightarrow t=0$.

In 2012, Madjid Eshaghi Gordji et.al proved the following result [26].

Theorem 2.([26]) Let $(X, \leq)$ be a partially ordered set and suppose that there exists a metric $d$ in $X$ such that $(X, d)$ is a complete metric space. Let $f: X \rightarrow X$ be an increasing mapping such that there exists an element element $x_{0} \in X$ with $x_{0} \leq f\left(x_{0}\right)$. Suppose that there exists $\beta \in \mathfrak{R}$ and $\psi \in \Psi$ such that

$\psi(d(f(x), f(y))) \leq \beta(\psi(d(x, y))) \psi(d(x, y))$

for each $x, y \in X$ with $x \geq y$.

Assume that either $f$ is continuous or $X$ is such that

if an increasing sequence $x_{n} \rightarrow x \in X$, then $x_{n} \leq x, \forall n$.

Then $f$ has a fixed point. Besides if

for each $x, y \in X$, there exists $z \in X$ which is comparable to $x$ and $y$.

Then ${ }^{f}$ has a unique fixed point.

Remark. In [27], it is proved that the condition (1.2) is equivalent to the following:

every pair of elements in $X$ has a lower bound or an upper bound.

\section{REVIEW}

In this section we point out the following two points. First point. The theorem 2 can be easily obtained from theorem 1, so that the longer proof of theorem 2 is not necessary. In fact, we can define a new metric as follows

$$
D(x, y)=\psi(d(x, y)), \forall x, y \in X .
$$

By using the property of $\psi$ we can easy to prove $(X, D)$ is a complete metric space. In fact, From $(a)(b)(c)(d)$ we have

(1) $\psi(d(x, y)) \geq 0$, and

$\psi(d(x, y))=0 \Leftrightarrow d(x, y)=0 \Leftrightarrow x=y, \forall x, y \in X ;$

$\psi(d(x, y))=\psi(d(y, x)), \forall x, y \in X$;

(3) $\psi(d(x, y)) \leq \psi(d(x, z))+\psi(d(z, y)), \forall x, y, z \in X$;

(4) $\psi\left(d\left(x_{n}, y_{n}\right)\right) \rightarrow 0 \Leftrightarrow d\left(x_{n}, y_{n}\right) \rightarrow 0$ as $n \rightarrow \infty$.

That is, $(X, \psi(d(\cdot, \cdot)))$ is a complete metric space. Since $T$ is $\psi$-Geraghty-contraction in complete metric space $(X, d)$, it is easy to see that, $T$ is a Geraghty contraction in complete metric space $(X, D)$.Meanwhile, a sequence $\left\{x_{n}\right\} \subseteq X$ converges to a point $x$ in metric

$d$ if and only if it converges to this point $x$ in metric $D$. On the other hand, $d(x, T x)=0$ if and only if $D(x, T x)=0$

Therefore, we apply the theorem 1 to metric space $(X, D)$, the theorem 2 can be obtained.

Second point. The existence of solution for a initial-value problem presented in [2] does not needed the application of theorem 2, we can also apply theorem 1 to get the the existence of solution for this initial-value problem and to get more generalized result. In fact that, by using the condition in theorem 2 we get the inequality $(A)$, that is

$$
d(F u, F v) \leq \lambda\left(T+2 \sqrt{\frac{T}{\pi}}\right) \ln (d(u, v)+1) \leq \ln (d(u, v)+1) .
$$

In this review we use another way to continuous the proof as follows. From $(A)$ we obtain

$$
d(F(u), F(v)) \leq \beta(d(u, v)) d(u, v),
$$

for all $u \geq v$,where

$$
\beta(u, v)= \begin{cases}\frac{\ln (d(u, v)+1)}{d(u, v)}, & \text { if } d(u, v) \neq 0 \\ 0, & \text { if } d(u, v)=0 .\end{cases}
$$

It is obvious that $\beta \in \mathfrak{R}$. Therefore we can apply the theorem 1 to get the conclusion of theorem 2 .

Furthermore, we can apply the theorem 1 to get more 
generalized result for the application to ordinary differential equation. In fact, if we use the following condition (2') to replace the condition (2), the conclusion of theorem 2 can be more generalized.

(2') there exists a constant $\lambda \leq \frac{1}{T+2 \sqrt{\frac{T}{\pi}}}$ such that

$0 \leq F\left(x, t, s_{2}, p_{2}\right)-F\left(x, t, s_{1}, p_{1}\right) \leq \lambda\left(\phi\left(s_{2}-s_{1}+p_{2}-p_{1}+1\right)\right)$

for all $\left(s_{1}, p_{1}\right),\left(s_{2}, p_{2}\right) \in R \times R$ with $s_{1} \leq s_{2}, p_{1} \leq p_{2}$.

where $\phi:[0,+\infty) \rightarrow[0,+\infty)$ is a function with the condition:

$\frac{\phi(t)}{t}<1, \forall t>0, \frac{\phi\left(t_{n}\right)}{t_{n}} \rightarrow 1 \Rightarrow t_{n} \rightarrow 0$ as $n \rightarrow+\infty$.

In fact that, by using condition $\left(2^{\prime}\right)$ we can obtain

$$
d(F u, F v) \leq \phi(d(u, v)),
$$

for all $u \geq v$, which implies

$$
d(F(u), F(v)) \leq \beta(d(u, v)) d(u, v)
$$

where

$$
\beta(t)= \begin{cases}\frac{\phi(t)}{t}, & \text { if } t \neq 0 \\ 0, & \text { if } t=0\end{cases}
$$

Since $\beta \in \Re$, we can use theorem 1 to get the following more generalized conclusion.

Theorem 3. Consider the application to ordinary differential equations problem with the following conditions:

(1) for any $c>0$ with $|s|<c$ and $|p|<c$, the function $F(x, t, s, p)$ is uniformly Holder continuous in $X$ and $t$ for each compact subset of $(R \times I)$;

(2') there exists a constant , $\lambda \leq \frac{1}{T+2 \sqrt{\frac{T}{\pi}}}$ such that $0 \leq F\left(x, t, s_{2}, p_{2}\right)-F\left(x, t, s_{1}, p_{1}\right) \leq \lambda\left(\phi\left(s_{2}-s_{1}+p_{2}-p_{1}+1\right)\right)$ for all $\left(s_{1}, p_{1}\right),\left(s_{2}, p_{2}\right) \in R \times R$ with $s_{1} \leq s_{2}, p_{1} \leq p_{2}$, where $\phi:[0,+\infty) \rightarrow[0,+\infty)$ is a function with the condition:

$$
\frac{\phi(t)}{t}<1, \forall t>0, \frac{\phi\left(t_{n}\right)}{t_{n}} \rightarrow 1 \Rightarrow t_{n} \rightarrow 0 .
$$

(3) $F$ is bounded for bounded $s$ and $p$.

Then the existence of a lower solution for the initial-value problem (2.2) provides the existence of the unique solution of the problem (2.1).

If chose $\phi(t)=\ln (t+1)$, the theorem 3.1 reduce the theorem 2.2. If chose

$$
\phi(t)=\left\{\begin{array}{l}
t^{2}, \quad \text { if } 0 \leq t \leq \frac{1}{2} \\
t-\frac{1}{4}, \quad \text { if } \frac{1}{2}<t .
\end{array}\right.
$$

\section{REFERENCES}

[1] Khan, MS, Swaleh, M, Sessa, S: Fixed point theorems by altering istances between the points. Bull. Aust. Math. Soc. 30(1), 1-9(1984)

[2] Dhutta, P, Choudhury, B: A generalization of contractions in partially ordered metric spaces. Appl. Anal. 87, 109-116 (2008)

[3] Rhoades, BE: Some theorems on weakly contractive maps. Nonlinear Anal. 47, 2683-2693 (2001)

[4] Aydi, H, Karapnar, E, Bessem, S: Fixed point theorems in ordered abstract spaces. Fixed Point Theory Appl. 2012, 76 (2012)

[5] Nieto, JJ, Pouso, RL, Rodríguez-López, R: A fixed point theorem for contraction type maps in partially ordered metric spaces and application to ordinary differential equations. Proc. Am. Math. Soc. 135, 2505-2517 (2007)

[6] Gordji, ME, Baghani, H, Kim, GH: Coupled fixed point theorems or contraction mapping induced by cone ball-metric in partially rdered spaces. Discrete Dyn. Nat. Soc. 2012, art. no. 981517 2012)

[7] Sintunavarat, W, Cho, YJ, Kumam, P: Existence, regularity and tability properties of periodic solutions of a capillarity equation in the presence of lower and upper solutions. Fixed Point Theory Appl. 2012, 128 (2012)

[8] Obersnel, F, Omari, P, Rivetti, S: A generalization of eraghty' s theorem in partially ordered metric spaces and pplications to ordinary differential equations. Nonlinear Anal., eal World Appl. 13, 2830-2852 (2012)

[9] Sastry, K, Babu, G: Some fixed point theorems by altering istance between the points. Indian J. Pure Appl. Math. 30, 641-647 (1999)

[10] Amini-Harandi, A, Emami, H: A fixed point theorem for contraction type maps in partially ordered metric spaces and application to ordinary differential equations. Nonlinear Anal. 72, 2238-2242 (2010)

[11] Harjani, J, Sadarangni, K: Fixed point theorems for weakly ontraction mappings in partially ordered sets. Nonlinear Anal. 71, 3403-3410 (2009)

[12] Burgic, D, Kalabusic, S, Kulenovic, M: Global attractivity esults for mixed monotone mappings in partially ordered complete etric spaces. Fixed Point Theory Appl. 2009, Article ID 7624782009

[13] Ciric, L, Cakid, N, Rajovic, M, Uma, J: Monotone generalized onlinear contractions in partially ordered metric spaces. Fixed oint Theory Appl. 2008, Article ID 131294 (2008)

[14] Gnana Bhaskar, T, Lakshmikantham, V: Fixed point theorems in artially ordered metric spaces and applications. Nonlinear Anal. 65, 1379-1393 (2006)

[15] Lakshmikantham, V, Ciric, L: Coupled fixed point theorems for nonlinear contractions in partially ordered metric spaces. Nonlinear Anal. 70, 4341-4349 (2009)

[16] Nieto, JJ, Rodriguez-López, R: Contractive mapping theorems n partially ordered sets and applications to ordinary differential equations. Order 22, 223-239 (2005)

[17] Nieto, JJ, Rodriguez-López, R: Existence and uniqueness of ixed point in partially ordered sets and applications to ordinary ifferential equations. Acta Math. Sin. 23, 2205-2212 (2007)

[18] O' Regan, D, Petrusel, A: Fixed point theorems for generalized ontractions in ordered metric spaces. J. Math. Anal. Appl. 341,1241-1252 (2008)

[19] Harjani, J, Sadarangni, K: Generalized contractions in artially ordered metric spaces and applications to ordinary ifferential equations. Nonlinear Anal. 72, 1188-1197 (2010)

[20] Fangfang Yan, Yongfu Su, Qiansgeng Feng, A new contraction mapping principle in partially ordered metric spaces and applications to ordinary differential equations, Fixed Point Theory and Applications 2012, 2012:152 
[21] Wasfi Shatanawi and Mihai Postolache, Common xed point theorems for dominating and weak annihilator mappings in ordered metric spaces, Fixed Point Theory and Applications 2013, 2013:271

[22] Wasfi Shatanawi, Mihai Postolache, Common xed point results of appings for nonlinear contraction of cyclic form in ordered metric spaces, Fixed Point Theory and Applications 2013, 2013:60

[23] Erdal Karapinar, Wasfi Shatanawi, and Zead Mustafa, Quadruple ixed Point Theorems under Nonlinear Contractive Conditions in Partially Ordered Metric Spaces, Journal of Applied Mathematics Volume 2012 (2012), Article ID 951912, 17 pages

[24] W. Shatanawi, Some xed point results for a generalized -weak ontraction mappings in orbitally metric spaces, Chaos, Solitons nd Fractals 45 (2012), 520-526

[25] Amini-Harandi. A, Emami, H: A fixed point theorem for contraction type maps in partially ordered metric spaces and application to ordinary differential equations. Nonlinear Anal. 72,2238-2242 (2010)

[26] Madjid Eshaghi Gordji, Maryam Ramezani1, Yeol Je Cho and Saeideh Pirbavafa, A generalization of Geraghtys theorem in partially ordered metric spaces and applications to ordinary differential equations, Fixed Point Theory and Applications 2012, 2012:74

[27] Nieto, JJ, Rodrguez-Lpez, R: Contractive mapping theorems in partially ordered sets and applications to ordinary differential $\begin{array}{llll}\text { equations. } & \text { Order. } & 22, & 23-239\end{array}$ Doi:10.1007/s11083-005-901 8-5

[28] Geraghty, M: On contractive mappings. Proc Amer Math Soc. 40, 604-608 (1973). doi:10.1090/S0002-9939-1973-0334176-5

[29] Agarwal, RP, El-Gebeily, MA, O'regan, D: Generalized contractions in partially ordered metric spaces. Appl Anal. 87,109-116 (2008). doi:10.1080/00036810701556151

[30] Ran, ACM, Reurings, MCB: A fixed point theorem in partially ordered sets and some applications to matrix equations. Proc Amer Math Soc. 132, 1435-1443 (2004). doi:10.1090/S0002-9939-03-07220-4

[31] Radenović, S, Kadelburg, Z, Jandrlic, D, Jandrlic, A: Some results on weakly contractive maps. Bull Iran Math Soc. (in press)

[32] Radenović, S, Kadelburg, Z: Generalized weak contractions in partially ordered metric spaces. Comput Math Appl. 60, 1776-1783 (2010). doi:10.1016/j.camwa.2010.07.008 